\title{
The Evaluation of the Use of AFO (Ankle Foot Orthotics) with the MOXFQ (Manchester-Oxford Foot Questionnaire) Method
}

\author{
Bayu Bawono ${ }^{1}$, Paulus Wisnu Anggoro ${ }^{2}$ \\ Department of Industrial Engineering \\ Universitas Atma Jaya Yogyakarta \\ Yogyakarta, Indonesia \\ 1bajubawono@gmail.com, \\ ²pauluswisnuanggoro@ymail.com
}

\author{
M. Tauviqirrahman ${ }^{3}$, A.P. Bayuseno ${ }^{4}$, J. Jamari ${ }^{5}$ \\ Department of Mechanical Engineering \\ Universitas Diponegoro \\ Semarang, Indonesia
}

\begin{abstract}
This research aims to find the influence of the insole in the shoe for the patient who suffered from disorders of the feet. Diabetic patients generally experience a disruption in the feet. This disorder is a stabbing pain when the patient performs activities. The patient is asked to use footwear Ankle Foot Orthosis (AFO) results of design that are already adapted to the shape of the user's feet during 28 days (4 weeks). At the end of the period, the patient is prompted to answer the questioner that consists of 16 questions. The questions are organized according to Manchester-Oxford Foot of a Questionnaire model (MOXFQ) to assess the response of special foot/ankle and General happens on feet and ankles. The response was measured by a score of 0-4 (strongly agree to strongly disagree) of respondents $\mathbf{2}$ consecutive female patients experience pain in the feet by using a regular foot, footwear with an average age of 72 years $(65$ and 80$)$. They independently completed the questionnaire during the use of AFO. The MOXFQ an average of 2 months. The results obtained in the first patients experienced an improvement of conditions of the foot with the score average $3.75(12 / 16$ answers in the form of a score of 4 and the rest score 3 ). This means going on a reduction of pain significantly in amount with a percentage score a maximum of $94 \%$. Patient 2 undergoing repair of foot conditions with the average score 2.97 . This means going on a reduction of pain significantly in amount with a percentage score a maximum of $74 \%$. The difference is due to the characteristics of the age, weight, height, as well as the profile of the soles of the feet are different. The second patient had a foot condition and a heavier weight.
\end{abstract}

\section{Keywords-AFO; MOXFQ; MFPDQ; PROM}

\section{INTRODUCTION}

On current conditions, there is the need of the customers who urged to do the evaluation of the problem with scientific methods for foot and ankle through procedure surgery, such as process operation at the foot of which are often associated with the the sense of patient dissatisfaction the high (between $20 \%$ and $30 \%$ ) and the process litigation [1;2;3;4;5]. Process evaluation the activities of the recovery of the foot the right need diverse implementation jobs the according to the standard with the method of assessment results that is right $[6 ; 7 ; 8 ; 9 ; 10]$. The process used to improve support executor for process use of patient-reported outcomes of actions (PROM). The utilization of PROM, to it is recommended to run with evaluating the results of treatment and repair process of the foot or replacement section joints [11].

The measurement results of the improvement of conditions of the foot that is in the feel the patient it is suitable for assessing the success rate operation on all section walk as well as the ankle. This is caused because the distance patients experienced the burden of a complex structure, with many parts of the foot that moves and loaded by the body mutually related, so repair the problem or process of care in one part can have the effect of improvements in other parts of the body [12]. Almost all the patients usually have some problems related in more than one part of the foot or ankle, especially if they have a history of arthritis or the congenital disorder that affects, or require correction of recovery or healing, over a period of therapy.

The service of process improvement to solve the problems of the foot as well as part ankle walk aimed at precautionary measures or improvements abnormalities of the feet and to improve physical patients with using a process of physical therapy, orthopedic surgery, footwear orthoses, and the drug.

Patients who experiencing foot problems, as well as the ankle for a variety causes include, is due to the condition of the default disability leg like foot deformities, both types of congenital defects secondary to a wide range of chronic conditions such as brain damage or bone arthritis, and conditions change others such as acute injury like sprains and fractures. The World Health Organization and classification function international classify the type of disability and health (ICF) (WHO 2001) with differentiated body structure disorder based on activity limitation and prohibition of participating, and now includes a special thing to be applied on a version for children and youth (WHO 2004 ) as reported by [2].

Manchester-Oxford Foot Questionnaire (MOXFQ 2011; developed in The University Of Oxford, United Kingdom) $[13 ; 14]$ is the system PROM which was originally developed by using techniques of interviews with patients who have a foot who should undergo a process of operation and developed at the Manchester leg pain and disability questionnaire (MFPDQ)[15] as basic research. The process of developing 
MFPDQ conducted in patients has been involved with the interview-based on information and complaints the community of patients with a variety of problems conditions of the foot and ankle. Change of conditions of the foot that is created based on the content and the response of the patients used to produce a product that is made with AFO shoes size (MOXFQ) the more suitable for process recovery through procedures 13 surgery including the addition assessment of questioner about the severity of the foot conditions like flavor pain parts of the legs or ankles on time the night and day.

This paper was compiled based on assessment report response the patient through MOXFQ on diabetic melitus patients experiencing difference deformities the given before and after using design and fabrication of custom shoe orthotic insole (AFO) in Figure 1 as reported by [21] and [22], it has been successfully developing the product for the patient to do activity everyday experiments for both patients during two months usage as shown in Figure 2.

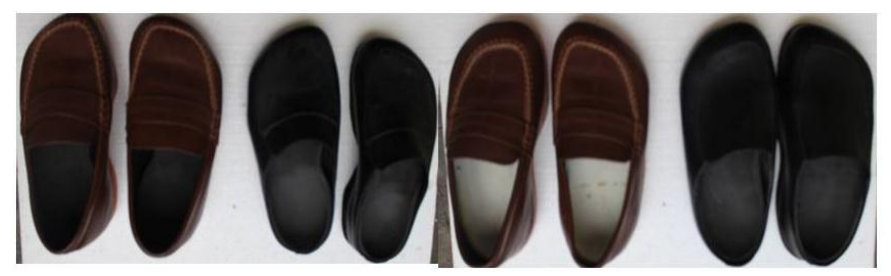

Fig. 1. Product AFO for patient diabetes

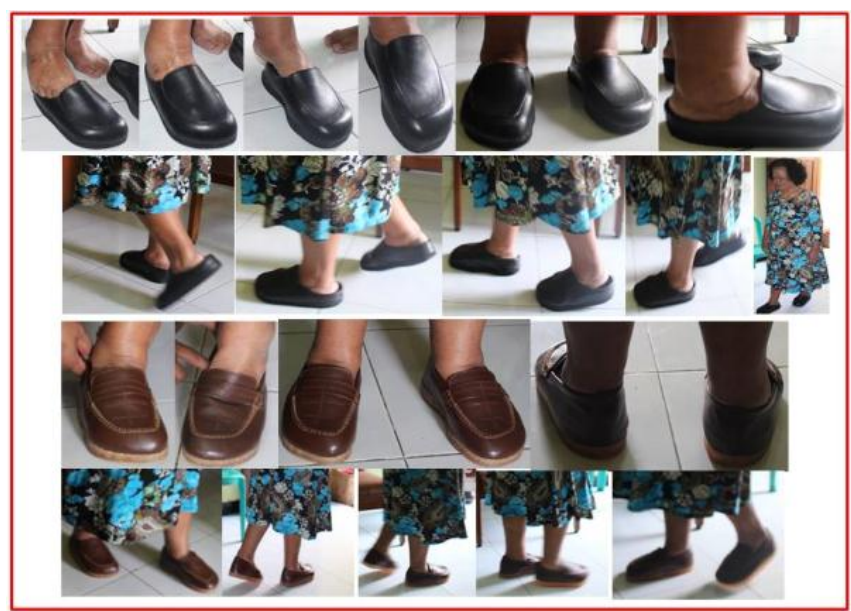

Fig. 2. Trial activity an AFO for two patient

The goal of this research is to assess whether MOXFQ can detect those changes. The second objective was to assess whether the magnitude of the changes that are detected by the MOXFQ Design Form with the patient's assessment.

The patient performs activities wearing AFO at least 4 hours a day for two months after the action the improvement of conditions foot or ankle, which would be expected to show major changes to the comfort of the patient. The purpose of first is the use of the questionnaire is to assess System MOXFQ can detect changes patient comfort. The second objective is to assess the level of change that is observed by the results of the design of MOXFQ in patients with giving an assessment about the level of success of changes that occur after using the AFO's shoes. this paper the results of the MOXFQ assessment on two diabetic patients votes on the circumstances before and after the use of for two months after the use of AFO's shoes, has resulted in significant improvements and the shows a big change. The purpose of the study was to assess whether MOXFQ can detect those changes. The second objective is to assess the magnitude of the changes that are detected by the MOXFQ in accordance with the assessment of the patient to change the level of convenience that has occurred after use of AFO's shoes that's been designed and made earlier by [22].

\section{MATERIAL \& MethodS}

Two diabetic patients with high risk of scale and does not have a history of the history of an amputee was chosen as an object in this paper. Two of female patients between the ages of 65 to 80 years old. Both of them are already suffering from diabetes for more than two decades. Both of them often experience pain when using the standard form of shoe insole that doesn't match the shape of the legs of the patient. Shoes or sandals that are given are often not durable because it is easy to tear due to bony swollen on the second leg of the patient (Figure 2).

Two pairs of shoes AFO that is already designed and fabricated by [21] has been used on both patients since the beginning of December 2017 until the end of February 2018. The time period around 3 this month was given to the two patients for using the AFO's shoes on a few selected fields and determined together. Remember both old patients, especially patients both a fat with a body weight of about $75 \mathrm{~kg}$, then the field of the road that passes for daily activity is in the House (tiled flooring and down the stairs), the environment (paved roads, rocky land). The use of shoes is a minimum of 4 hours per day for two months.

After two months of testing the use of the shoe, AFO was completed by the patient then both given form questionnaire MOXFQ and asked to fill in with their own answers. Form questionnaire MOXFQ and the results of the second response of the patient can be presented in Tables 1 and 2 .

TABLE I. THE MOXFQ_STANDARD QUESTIONNAIRE FOOT

\begin{tabular}{|c|c|c|c|c|c|}
\hline \multirow{2}{*}{$\begin{array}{l}\text { Circle as appropriate: } \\
\text { RIGHT / LEFT FOOT } \\
\text { During the past } 4 \text { weeks } \text { this } \\
\text { has applied to me: }\end{array}$} & \multicolumn{5}{|c|}{ Please tick $\checkmark$ one box for each statement } \\
\hline & $\begin{array}{l}\text { None } \\
\text { of the } \\
\text { time }\end{array}$ & Rarely & $\begin{array}{l}\text { Some } \\
\text { of the } \\
\text { time }\end{array}$ & $\begin{array}{c}\text { Most } \\
\text { of the } \\
\text { time }\end{array}$ & $\begin{array}{c}\text { All of } \\
\text { the } \\
\text { time }\end{array}$ \\
\hline 1. I have pain my foot & $\square$ & $\square$ & $\square$ & $\square$ & $\square$ \\
\hline $\begin{array}{l}\text { 2. I avoid walking long } \\
\text { distances because of pain in } \\
\text { my foot }\end{array}$ & $\square$ & $\square$ & $\square$ & $\square$ & $\square$ \\
\hline $\begin{array}{l}\text { 3. I change the way I walk due } \\
\text { to pain in my foot }\end{array}$ & $\square$ & $\square$ & $\square$ & $\square$ & $\square$ \\
\hline $\begin{array}{l}\text { 4. I walk slowly because of } \\
\text { pain in my foot }\end{array}$ & $\square$ & $\square$ & $\square$ & $\square$ & $\square$ \\
\hline $\begin{array}{l}\text { 5. I have to stop and rest my } \\
\text { foot bacause of pain }\end{array}$ & $\square$ & $\square$ & $\square$ & $\square$ & $\square$ \\
\hline $\begin{array}{l}\text { 6. I avoid some hard or rough } \\
\text { surfaces because of pain in } \\
\text { my foot }\end{array}$ & $\square$ & $\square$ & $\square$ & $\square$ & $\square$ \\
\hline $\begin{array}{l}\text { 7. I avoid standing for a long } \\
\text { time because of pain in my } \\
\text { foot }\end{array}$ & $\square$ & $\square$ & $\square$ & $\square$ & $\square$ \\
\hline
\end{tabular}




\begin{tabular}{|c|c|c|c|c|c|}
\hline \multirow{2}{*}{$\begin{array}{l}\text { Circle as appropriate: } \\
\text { RIGHT / LEFT FOOT } \\
\text { During the past } 4 \text { weeks } \\
\text { has applied to me: }\end{array}$} & \multicolumn{5}{|c|}{ Please tick $\checkmark$ one box for each statement } \\
\hline & $\begin{array}{l}\text { None } \\
\text { of the } \\
\text { time }\end{array}$ & Rarely & $\begin{array}{l}\text { Some } \\
\text { of the } \\
\text { time }\end{array}$ & $\begin{array}{l}\text { Most } \\
\text { of the } \\
\text { time }\end{array}$ & $\begin{array}{l}\text { All of } \\
\text { the } \\
\text { time }\end{array}$ \\
\hline $\begin{array}{l}\text { 8. I catch the bus or use the car } \\
\text { instead of ealking, because } \\
\text { of pain in my foot }\end{array}$ & $\square$ & $\square$ & $\square$ & $\square$ & $\square$ \\
\hline $\begin{array}{l}\text { 9. I feel self-conscious about } \\
\text { my foot }\end{array}$ & $\square$ & $\square$ & $\square$ & $\square$ & $\square$ \\
\hline $\begin{array}{l}\text { 10. I feel self-concious about } \\
\text { the shoes I have to wear }\end{array}$ & $\square$ & $\square$ & $\square$ & $\square$ & $\square$ \\
\hline $\begin{array}{l}\text { 11. The pain in my foot is more } \\
\text { painful in the evening }\end{array}$ & $\square$ & $\square$ & $\square$ & $\square$ & $\square$ \\
\hline $\begin{array}{l}\text { 12. I get shooting pains in my } \\
\text { foot }\end{array}$ & $\square$ & $\square$ & $\square$ & $\square$ & $\square$ \\
\hline $\begin{array}{l}\text { 13. The pain in my foot } \\
\text { prevents me from carrying } \\
\text { out my work/everyday } \\
\text { activities }\end{array}$ & $\square$ & $\square$ & $\square$ & $\square$ & $\square$ \\
\hline $\begin{array}{l}\text { 14. I am unable to do all my } \\
\text { social or recreational } \\
\text { activities because of pain in } \\
\text { my foot }\end{array}$ & $\square$ & $\square$ & $\square$ & $\square$ & $\square$ \\
\hline
\end{tabular}

15. During the past 4 weeks how would you describe the pain you usually have in your foot? (please tick one box)

None Very mild Mild Moderate Severe

$\square \quad \square \quad \square \quad \square \quad \square \quad \square$

16. During the past 4 weeks have you been troubled by pain from your foot in bed at night? (please tick one box)

$$
\begin{array}{cccc}
\text { No nights } & \begin{array}{c}
\text { Only } 1 \text { or } 2 \\
\text { nights }
\end{array} & \begin{array}{c}
\text { Some } \\
\text { nights }
\end{array} \quad \text { Most nights } & \begin{array}{c}
\text { Every } \\
\text { night }
\end{array}
\end{array}
$$

${ }^{1}$ The foot to be assessed may be indicated here. Alternatively, each question may be customized to the right foot with all questions then repeated and customized to the left foot.

TABLE II. RESPONSE QUESTIONAIRE PATIENT 1 AND 2 BEFORE AND AFTER Use AFO (PAIN FoOT/ANKLE WhEN Do ACTIVITY)

\begin{tabular}{|l|l|c|c|c|c|c|c|c|c|}
\hline \multirow{2}{*}{ No } & Question & \multicolumn{3}{|c|}{ Before (B) } & \multicolumn{5}{|c|}{ After (A) } \\
\cline { 2 - 9 } & $\mathrm{L}_{1}$ & $\mathrm{R}_{1}$ & $\mathrm{~L}_{2}$ & $\mathrm{R}_{2}$ & $\mathrm{~L}_{1}$ & $\mathrm{R}_{1}$ & $\mathrm{~L}_{2}$ & $\mathrm{R}_{2}$ \\
\hline 2 & $\begin{array}{l}\text { Pain on } \\
\text { my foot }\end{array}$ & 1 & 1 & 1 & 2 & 4 & 4 & 4 & 4 \\
\hline 3 & $\begin{array}{l}\text { Walking } \\
\text { long } \\
\text { distance }\end{array}$ & 1 & 1 & 0 & 1 & 4 & 4 & 3 & 3 \\
\hline $\begin{array}{l}\text { Change } \\
\text { position } \\
\text { when } \\
\text { walking }\end{array}$ & 1 & 1 & 0 & 1 & 4 & 4 & 3 & 3 \\
\hline 4 & $\begin{array}{l}\text { Walking } \\
\text { slowly }\end{array}$ & 1 & 1 & 0 & 1 & 4 & 4 & 2 & 3 \\
\hline 5 & $\begin{array}{l}\text { Stop and } \\
\text { rest foot }\end{array}$ & 1 & 1 & 0 & 1 & 4 & 4 & 3 & 3 \\
\hline 6 & $\begin{array}{l}\text { Walking } \\
\text { on hard } \\
\text { and rough } \\
\text { surface }\end{array}$ & 1 & 1 & 1 & 2 & 4 & 4 & 4 & 4 \\
\hline 7 & $\begin{array}{l}\text { Stand } \\
\text { long time }\end{array}$ & 0 & 0 & 0 & 1 & 3 & 3 & 2 & 3 \\
\hline 8 & $\begin{array}{l}\text { Speed } \\
\text { walking }\end{array}$ & 0 & 0 & 0 & 0 & 3 & 3 & 1 & 2 \\
\hline 9 & $\begin{array}{l}\text { Self- } \\
\text { conscious } \\
\text { when } \\
\text { walking }\end{array}$ & 0 & 0 & 0 & 1 & 3 & 3 & 3 & 3 \\
\hline
\end{tabular}

\begin{tabular}{|c|l|c|c|c|c|c|c|c|c|}
\hline \multirow{2}{*}{ No } & Question & \multicolumn{5}{|c|}{ Before (B) } & \multicolumn{4}{|c|}{ After (A) } \\
\cline { 2 - 9 } & $\mathrm{L}_{1}$ & $\mathrm{R}_{1}$ & $\mathrm{~L}_{2}$ & $\mathrm{R}_{2}$ & $\mathrm{~L}_{1}$ & $\mathrm{R}_{1}$ & $\mathrm{~L}_{2}$ & $\mathrm{R}_{2}$ \\
\hline 10 & $\begin{array}{l}\text { self- } \\
\text { conscious } \\
\text { when use } \\
\text { shoe }\end{array}$ & 1 & 1 & 0 & 1 & 4 & 4 & 3 & 3 \\
\hline 11 & $\begin{array}{l}\text { Sickness } \\
\text { every } \\
\text { morning }\end{array}$ & 1 & 1 & 0 & 1 & 4 & 4 & 3 & 3 \\
\hline 12 & $\begin{array}{l}\text { Feel } \\
\text { Shooting } \\
\text { pain }\end{array}$ & 1 & 1 & 0 & 1 & 4 & 4 & 3 & 3 \\
\hline 13 & $\begin{array}{l}\text { When do } \\
\text { activity } \\
\text { everiday }\end{array}$ & 1 & 1 & 0 & 1 & 4 & 4 & 3 & 3 \\
\hline 14 & $\begin{array}{l}\text { When do } \\
\text { social } \\
\text { activity }\end{array}$ & 0 & 0 & 0 & 1 & 3 & 3 & 2 & 3 \\
\hline 15 & $\begin{array}{l}4 \text { week } \\
\text { do } \\
\text { activity }\end{array}$ & 1 & 1 & 0 & 1 & 4 & 4 & 3 & 3 \\
\hline 16 & $\begin{array}{l}4 \text { week in } \\
\text { bed at } \\
\text { night }\end{array}$ & 1 & 1 & 0 & 2 & 4 & 4 & 3 & 4 \\
\hline Average score & 0.73 & 0.73 & 0.13 & 1.07 & 3.73 & 3.73 & 2.80 & 3.07 \\
\hline
\end{tabular}

The Response data in table 2 using Microsoft software Excell $2016^{\mathrm{TM}}$. The phases of the methodology of research carried out in this paper can be shown in Figure 3.

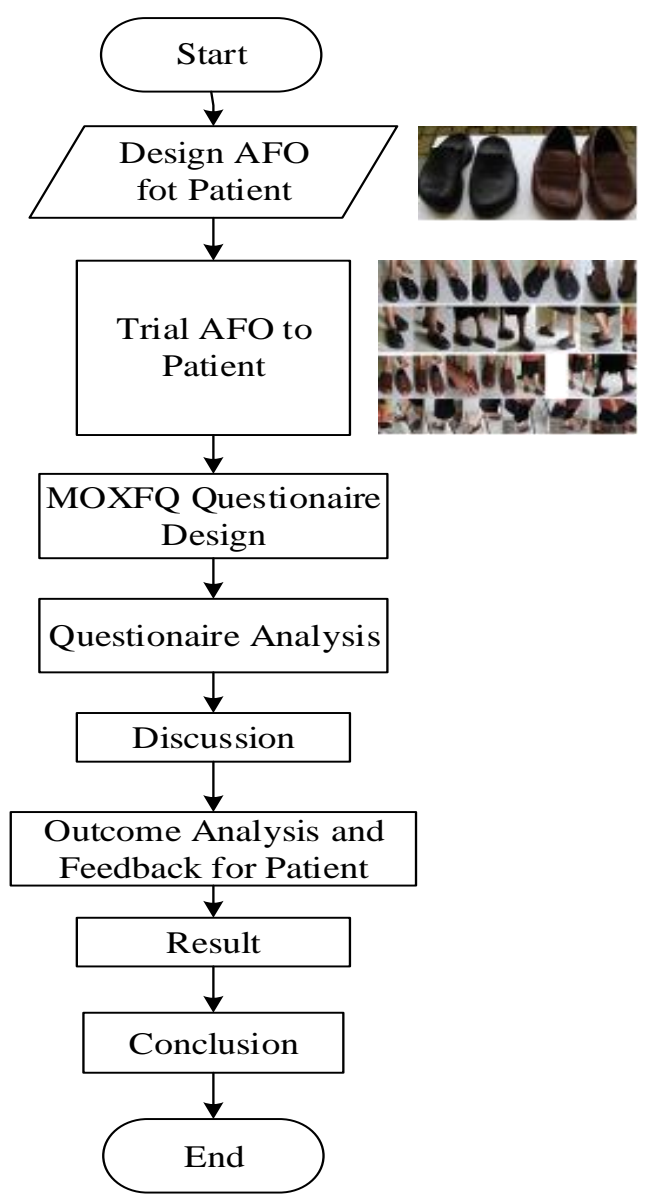

Fig. 3. Research Methodology 


\section{RESULT AND DISCUSSIONS}

This study uses two responding patients with a history of diabetic women with age both over 60 years. The main complaint is the pain in the legs when the patient performs activities on foot. This activity uses the shoes or sandals. The pain happens usually feels like needle hurt. The answer of respondents analyzed with statistic tools.

Response Manchester-Oxford Foot Questionnaire (MOXFQ) compared to at the time of the patient using speckle footwear AFO draft results. Patients that recruited is 2 adult patients who got problem the palm or the side of the foot, with an average age of 72 years (65 and 80). They independently fill out and responded with completed questionnaires, MOXFQ pre-usage, and usage during 3 months. Part of the observed overall leg section expert AOFAS (American Orthopedic Foot and Ankle Society) correspond to the 4 four regions of the foot/ankle foot.

Item as many as 16 questions and questions measured changes that are felt in the ankle/foot problem post wearing AFO.

Both patients answer a questionnaire and receive a clinical assessment of both pre-usage and after discharge. The foot section Patients who asked 16 item questions, the two patients experienced problems on the soles of the feet (100\%), ankles $(50 \%)$, middle (feet $50 \%$ ), hallux in $(100 \%)$, and the radius is small $(50 \%)$. The design of Insole based on the complaints of the respondents and questionnaire-based MOXFQ to produce the effect of improvement $(>0.8)$ and lower pain in the feet. The analysis that used to make changes in the value and effects of AFO size patient responses to transition items about foot problems, their ankles/MOXFQ better perform. The analysis of SF-36 and EQ-5 became lower. The similar analysis, performed on the patient's left and right to find that the response from MOXFQ it's worthy associated to the AOFAS. This evidence supports the MOXFQ appropriateness to assess all of the ankle and foot problem [11].

There is crucial want for systematic evaluation part of the palm, sidewalk, and ankle procedures improvements to the draft associated with level to age patients between 60 to $80 \%$ ) and conducted evaluation work requires a standard method of assessment results of the AFO. The Efforts are being made to increase the sustenance for the usage of patient-reported effect action improvements (which reflects the wishes of the user, rather than point of view designers AFO [12] results of the independent assessment team of experts, is considered better than the judge's own draft results AFO draft Results using Prom is recommended when evaluating the results of the combined draft. The results of the required size are suitable for assessing the success of on lowering pain areas of the foot soles, the side, and ankles due to they all include a complex structure with a lot of moving parts and interconnected [13] so that repair problems or treatments in single part can have an outcome for the other [14].

Upon interview respondent, often have more than one problematic in the ankle and feet, especially if they have a disorder arthritis or inherited disorder that disturbed, or require correction, more than one structure. Questionnaire (MOXFQ,
University of Oxford, United Kingdom) [15;16] is PROM was originally established using discussions with respondents having problems foot pain as a template. The making of MFPDQ has elaborated interviews with rspondents that with a variety of conditions of the foot and ankle. Changes made to content items and response categories to generate size (MOXFQ) is better suited to the context of handling in the form of a reduction in pain [15] comprising the accumulation factor about the severity of ache at night and the day. MOXFQ measurement of the properties originally used in patients suffering a hallux operation. Here, the questionnaire function with the level of reliability is good, structure factors, validity, and responsiveness $[15 ; 16]$. Nevertheless, the results of the measures that need to be validated for the user of the condition when the AFO will be used. Based on the evidence results of interview and data processing to support the acceptance, reliability and concurrent rationality to the MOXFQ, by the data that got from respondents who undergo therapy for a variety of the condition feet and ankles [18] of the respondents are examined, such as a medical experiment, the response of the measuring results its capability to identify the time of observations with the level of the rationality of the high [20]. This paper contains thevaluation of the response of the MOXFQ between the patients who were evaluated before and after the use of AFO and on average usage 2 months after the expected may indicate repair patient condition the great. The purpose of this research was to assess whether MOXFQ can detect those changes. The second objective was to assess whether the magnitude of the changes that are detected by the MOXFQ parallel with patient assessment level changes significantly. MOXFQ performance compared to AOFAS [24].

Materials and methods approval patients research that gained for study and all respondent agreed to join in the process research. Successive adult respondents, for 2 months from December 2017 until February 2018 using the AFO in activity throughout the day. The criteria used are the patients aged $\geq 18$ years of age, suffered a disruption on the feet, can understand the questionnaire and approved the research process. Exclusion criteria were patients undergoing surgery, amputation or local. They recruit and agree with the research officer at the House. The both patient calculated statistical analysis to detect changes in the entire sample, have $90 \%$, $\mathrm{p}<0.05$ to detect small effects in individual size 0.15 . The differences in Research with detected at $\mathrm{p}<0.05$ with $90 \%$ of patients are independently completed a questionnaire consisting of demographic items and MOXFQ), separately for each foot functioned. The SF-36 general health questionnaire (version II) [19,20] and EQ-5D[21,22] MOXFQ contains 16 items, each with five answer choices, consists of three separate fundamental dimensions: stand/run problems (7 items), leg pain (5 items), and the problems associated with social collaboration (4 items), including feelings of self-perception about the attendance of the foot of the pedestal-leg. The response of each assessed from 0-4, with 0 that represents the most severe response and 4 is the best response/ comfortable). This study is using MOXFQ to evaluate the context of reduction of pain in the feet and ankles, SF-36 contains 
questions as much as 36 items. This question concerns the 8 dimensions: physical functioning (PF), social functioning (SF), the role of the limitations because of the problem of physical (RP), role limitations due to emotional problems (FWD), mental health $(\mathrm{MH})$, energy/vitality $(\mathrm{EV})$, body $(\mathrm{P})$ and the public perception of health $(\mathrm{GH})$ for four weeks. Scores for each range 0 (low health)-100 (high health). EQ-5d is the size of a standard generic health with the status index value and consists of five questions on mobility, self-care, pain, activity as usual and psychological status with three possible the answer to each item (1, it doesn't matter; 2, moderate problems; 3, weight problems). MOXFQ, SF-36, and EQ-5d in February 2018. The answers to the questionnaire form the perceived changes in the foot or ankle problems compared to before the use of AFO.

The basic results of the study sample consist 2 patients with an average age of 72 years with all the are women. All of the changes represent a significant improvement from the health awareness subscale. Size effect for each of the 3 MOXFQ high scales: 0.86 (stand/walk), 0.98 (sick) and 0.87 (social collaboration), shows that the level of very large changes is detected after the use of AFO. The Application of the Questionnaire MOXFQ (while walking/standing, sick and social interaction) related with significant valuation AOFAS scale (each corresponds to 4 of the 4 regions of the foot/ankle), SF-36 (function physical, role physical, mental, social role function, mental health, energy, vitality, pain and general health perception) scale and EQ-5d; comparisons are also made with the patient rating items transitions and satisfaction. The result of a questionnaire that shown in Figure 4.

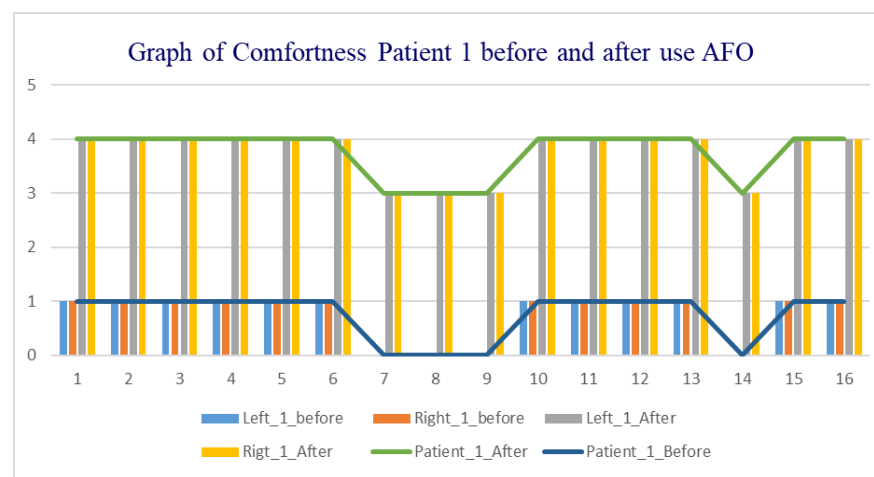

(a)

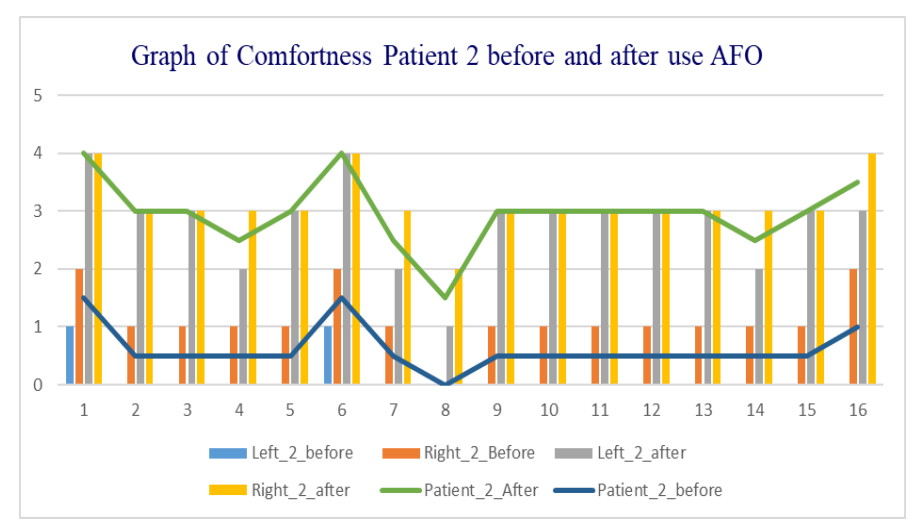

(b)

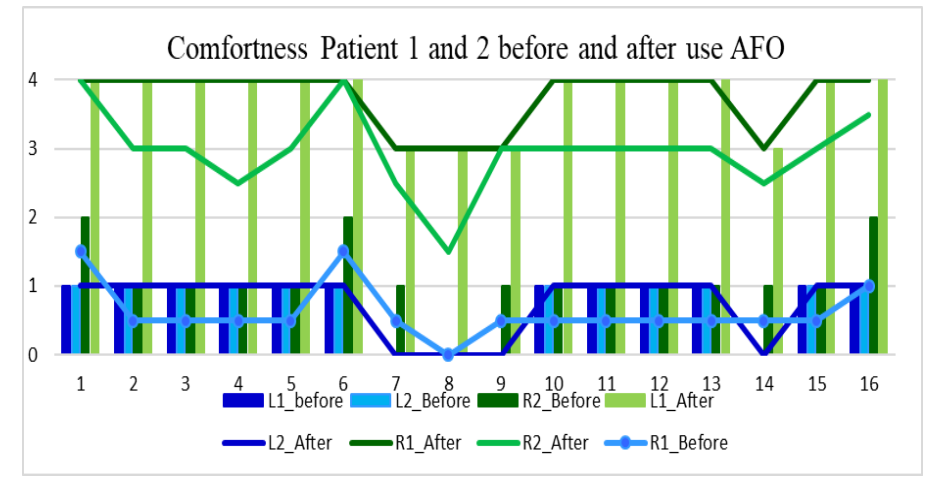

(c)

Fig. 4. (a) Comfortness For Patient 1, (b) Comfortness For Patient 2 (c) Comfortness For Patient 1 and 2.

Fig. (4a) Comfortness For Patient 1 (4b) Comfortness For Patient 2 (4c) Comfortness For Patient 1 and 2 shown the significance difference between $\mathrm{P}_{1}$ and $\mathrm{P}_{2}$ before and after use the AFO.

On the left foot patient's 1 (Fig. 4a.) in the initial conditions, the answers of the respondents ranged among 0 and 1 with a mean value of 0.73 . This value means the pain respondents is 'Most of the time'. After the use of AFO become increase in comfort with a score of 3.73 means the pain disappears 'None of the time'. The similar increase occurred on the right foot from the score 0.73 raise to score 3.73 .

On the left foot patient's 2 (Fig. 4b) on the initial conditions, the answers of the respondents ranged among 0 and 1 with a mean value of 0.13 . This value means that the respondents suffered extreme pain or 'All of the time'. After the use of AFO an increase in comfort with the score 2.73 means the pain is rarely appear or 'Rarely'. A similar increase occurred on the right foot from the score 1.07 raise to score 3.07

The increased of comfort in patients 1 and 2 (Fig. 4c) shown that wearing AFO will improve the significant comfort of patients by lowering the pain from the foot score between 0 to with the condition 'All of the time' and 'Most of the time', become a score 3-4 namely 'rarely' and 'None of the time "

\section{CONCLUSIONS}

The increased of comfort in patients 1 and 2 shown that wearing AFO will improve the significant comfort of patients by lowering the pain from the foot score between 0 to with the condition ' All of the time ' and ' Most of the time, become a score 3-4 namely ' rarely ' and ' None of the time "

- Patient $1\left(\mathrm{P}_{1}\right)$ answered with a score of 4 (12 questions) and a score of 3 (4 questions) with an average 3.75 (maximum scale 4) this showed his leg is improving conditions P1 with the pain disappear altogether (4 answer still appears to suggest the pain especially when standing too long, memgejar vehicles, recreational activities, and pain in the feet a particular moment) is valid on both legs (left and right) 
- Patient $2\left(\mathrm{P}_{2}\right)$ answered with a score of 4 (4 questions) and a score of 3 (10 questions) and average 2.97 this showed his leg is improving conditions $\mathrm{P}_{2}$ with pain is gone (4) completely (10 answer still appears to suggest the pain especially when standing for too long, walking, running, while wearing footwear). This difference is due to the older age of the $\mathrm{P}_{2}$ and greater weight)

- The average for both patient $\left(\mathrm{P}_{1}\right.$ and $\left.\mathrm{P}_{2}\right)$ has been helped by the use of the footwear. The result of $94 \% \mathrm{P}_{1}$ pain overall vanish, $\mathrm{P}_{2}$ around $74 \%$ of missing altogether and about $2 \%$ are still appears in certain moments of condition activity (rarely)

\section{ACKNOWLEDMENT}

The authors wish to thanks for supporting this research by PT. Idea Hidup Sistema Jakarta, PT. Hankook Delcam Indonesia Jakarta, Laboratory of production process University of Atma Jaya Yogyakarta, and CV TA Machinery Surakarta.

\section{REFERENCES}

[1] E.M. Roos, Validation of the Foot and Ankle Outcome Score for Ankle Ligament Reconstruction, Foot \& Ankle International, Vol. 22, No. 10/0ctober 2001, 788-794

[2] C. Morris, Development of the Oxford ankle foot questionnaire:finding out how children are affected by foot and ankle problems, Child: care, health and development, Vol.33, No. 5,pp 559-568, 2007, doi:10.1111/j.1365-2214.2007.00770.x

[3] J. Dawson, Responsiveness of the Manchester-Oxford foot questionnaire (MOXFQ) compared with AOFAS, SF-36 and EQ-5D assessments following foot or ankle surgery, Foot And Ankle, Vol. 94B, No. 2, February 2012, DOI:10.1302/0301-620x.94b2. 27634

[4] TG Thomas, Medical litigation and the foot. The Foot 1991;1:3-5.

[5] A. Atrey, Review of successful litigation against English health trusts in the treatment of adults with orthopaedic pathology: clinical governance lessons learned. J Bone Joint Surg [Am] 2010;92-A:1-6.

[6] D.P. O'Doherty, et al, The management of the painful first metatarsophalangeal joint in the older patient: arthrodesis or Keller's arthroplasty? J Bone Joint Surg [Br] 1990;72-B:839-842.
[7] J. Ferrari, Interventions for treating hallux valgus (abductovalgus) and bunions. Cochrane Database Syst Rev 2009;2:CD000964. http://onlinelibrary.wiley.com/doi/10.1002/14651858.CD000964.pub2/p df (date last accessed 30 November 2011).

[8] J. Parker, The problem with measuring patient perceptions of outcome with existing outcome measures in foot and ankle surgery. Foot Ankle Int 2003;24:56-60.

[9] Amadio PC. Outcomes measurements. J Bone Joint Surg [Am] 1993;75A:1583- 1584 .

[10] Fitzpatrick R, Fletcher A, Gore S, Quality of life measures in health care: I: applications and issues in assessment. BMJ 1992;305:10741077.

[11] V. Wylde, AW. Blom, The failure of survivorship. J Bone Joint Surg [Br] 2011;93B:569-570

[12] D. Tiberio, Pathomechanics of structural foot deformities. Phys Ther 1988;68:1840- 1849

[13] Dawson J, et al. A patient-based questionnaire to assess outcomes of foot surgery: validation in the context of surgery for hallux valgus. Qual Life Res 2006;15:1211-1222.

[14] Dawson J, Responsiveness and minimally important change for the Manchester-Oxford foot questionnaire (MOXFQ) compared with AOFAS and SF-36 assessments following surgery for hallux valgus. Osteoarthritis Cartilage 2007;15:918-931.

[15] AP Garrow, Development and validation of a questionnaire to assess disabling foot pain. Pain 2000;85:107-113.

[16] HB Kitaoka, Clinical rating systems for anklehindfoot, midfoot, hallux and lesser toes. Foot Ankle Int 1994;15:349-353.

[17] Ware-JE, The MOS 36-item short-form health survey (SF-36). I: Conceptual framework and item selection. Med Care 1992;30:473-483.

[18] Jenkinson C, Stewart-Brown S, Petersen S, Paice C. Assessment of the SF-36 version 2 in the United Kingdom. J Epidemiol Community Health 1999;53:46-50.

[19] No authors listed. EuroQol: a new facility for the measurement of health-related quality of life. Health Policy 1990;16:199-208.

[20] Brooks R. EuroQol: the current state of play. Health Policy 1996;37:5372.

[21] P.W. Anggoro, E. Saputra, M. Taufiqirrahman, J. Jamari, A.P. Bayuseno, A 3D dimensional finite element analysis of the insole shoe orthotic for foot deformities, International Journal of Applied Engineering Research, 12(15), 5254-5260, 2017

[22] P.W. Anggoro, B. Bawono, M. Tauviqirrahman, J. Jamari, A.P. Bayuseno, M. M. Avelina, Computer-aided reverse engineering system in the design and production of orthotic insole shoes for patients with diabetes. Cogent Engineering 